\title{
SUMMARY OF SCAN SITE 6
}

\author{
G. W. Moore, U. S. Geological Survey, La Jolla, California \\ and \\ G. F. Sharman, Scripps Institution of Oceanography, La Jolla, California
}

\section{OBJECTIVES OF DRILL HOLE}

The location surveyed for Site 6 is at latitude $41^{\circ} 02^{\prime} \mathrm{N}$, longitude $140^{\circ} 41^{\prime} \mathrm{W}$, and the water depth is approximately 4540 meters. Site 6 lies on a characteristic positive magnetic anomaly that has been correlated by Vacquier and others (1961) with a similar anomaly at Site 2 across the Mendocino Transform Fault to the south and offset 1170 kilometers to the east. In addition to testing the validity of the correlation, this drill hole will sample the cool-water microfossil sequence of the northeast Pacific to compare it with the sequence at Site 15 in the northwest Pacific, and with those at a series of sites arrayed to the south along the 140th meridian.

\section{SURVEY METHODS}

The survey of this site was made from the Argo between March 20-22, 1969. Positioning was by a satellite navigation system in which the refraction-correction function had failed. Fix precision is estimated at about 4 kilometers, and the fix frequency was less than 1 every two hours. Two noon positions were also plotted during the course of the survey. Magnetic-intensity traverses and acoustic-reflection profiles at $12,3.5$ and $0.1 \mathrm{kHz}$ were run on a grid 75 kilometers square, with tracks about 20 kilometers apart. On the accompanying subbottom profiles, a 5-second sweep was used, and the record of the bottom appears on the second sweep after firing. The spacing between hour marks is about 20 kilometers. Near this site a piston core was taken, and the heat flow was measured.

\section{NATURE OF SITE}

The sediment in this area is uniformly thin at about 40 meters. Surficial manganese nodules were caught by the corer; and, very pale orange brittle clay at a depth of 3 meters contains upper Pliocene coccoliths. This sediment overlies firm grayish-brown clay to the base of the core at 8 meters. The heat flow is about average at $1.3 \mu \mathrm{cal} / \mathrm{cm}^{2} \mathrm{sec}$.

\section{MICROPALEONTOLOGY \\ David Bukry \\ U. S. Geological Survey, La Jolla}

\section{General Comments}

Samples taken at 1.5 -meter intervals from the piston cores, recovered during the preliminary surveys of the proposed Deep Sea Drilling Project sites in the northeast Pacific, have been examined for calcareous nannofossils. The identified assemblages of nannofossils indicate that Pliocene sediment containing abundant discoasters is present in the upper 10 meters at only one place, Site 6. Elsewhere, only Pleistocene assemblages are present in the upper 10 meters. The abundant, widely distributed Holocene nannofossil, Emiliania huxleyi (Lohmann) is not represented in any of the samples examined.

Diatoms are common only in surface samples ( 0 to 1 centimeter) at Sites 1,2 and 4. Foraminifera are sparsely present in several samples from Sites 1, 2, 4, 5 and 6.

\section{SCAN-6-P}

Core length: 8.0 meters. A probable lower Pleistocene assemblage containing only C. pelagicus, Cyclococcolithus leptoporus var. A and var. B of McIntyre, Bé and Preikstas, with a few reworked specimens of Discoaster sp. aff. D. brouweri Tan is present at 164 to 165 centimeters. At 335 to 336 centimeters a diagnostic upper Pliocene assemblage, dominated by discoasters, is present. This assemblage includes Ceratolithus rugosus Bukry and Bramlette, Coccolithus doronicoides Black and Barnes, C. pelagicus, Cyclococcolithus leptoporus var. A, Discoaster pentaradiatus Tan, D. surculus Martini and Bramlette, and D. variabilis Martini and Bramlette. Samples below this are barren. 


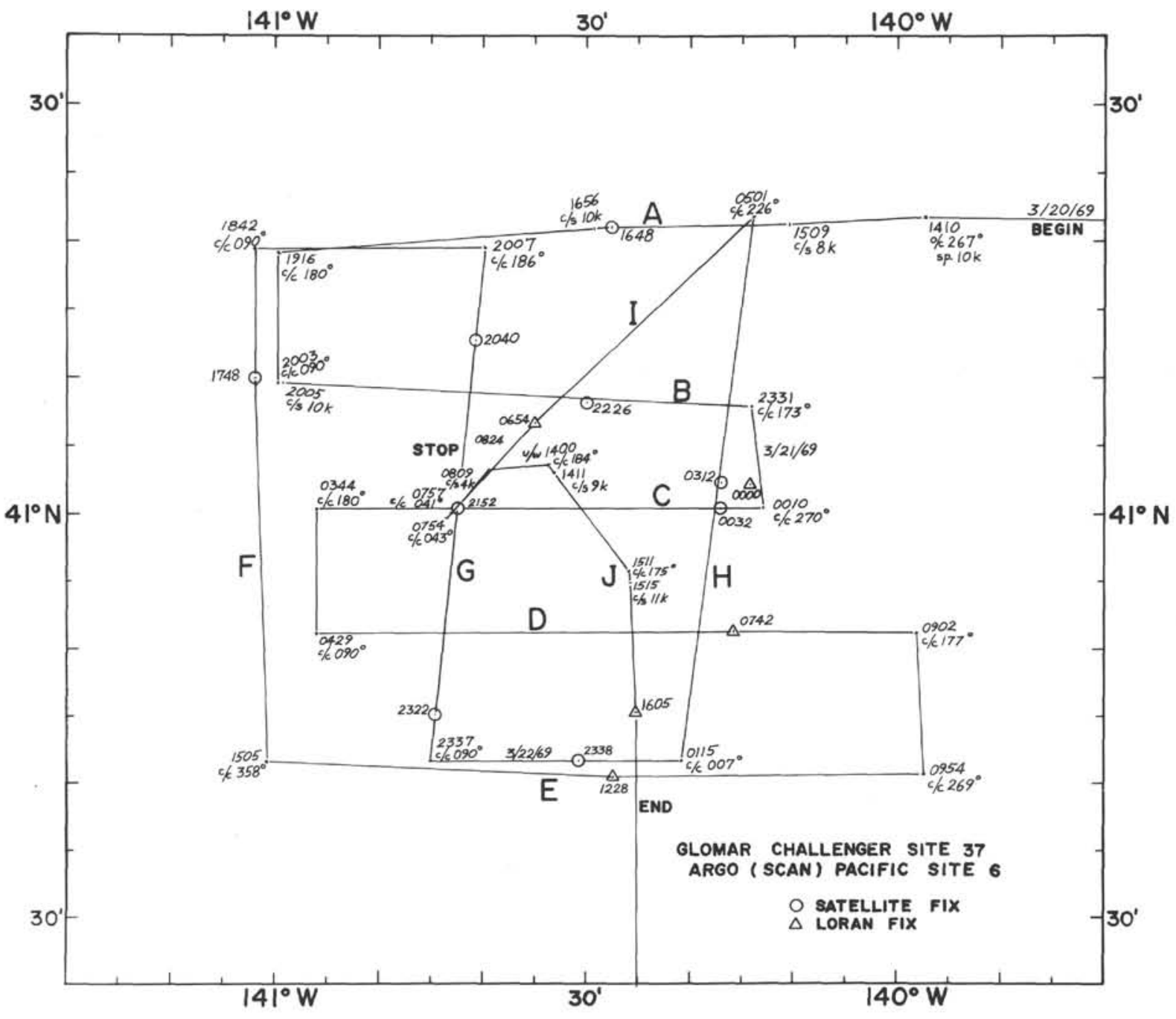




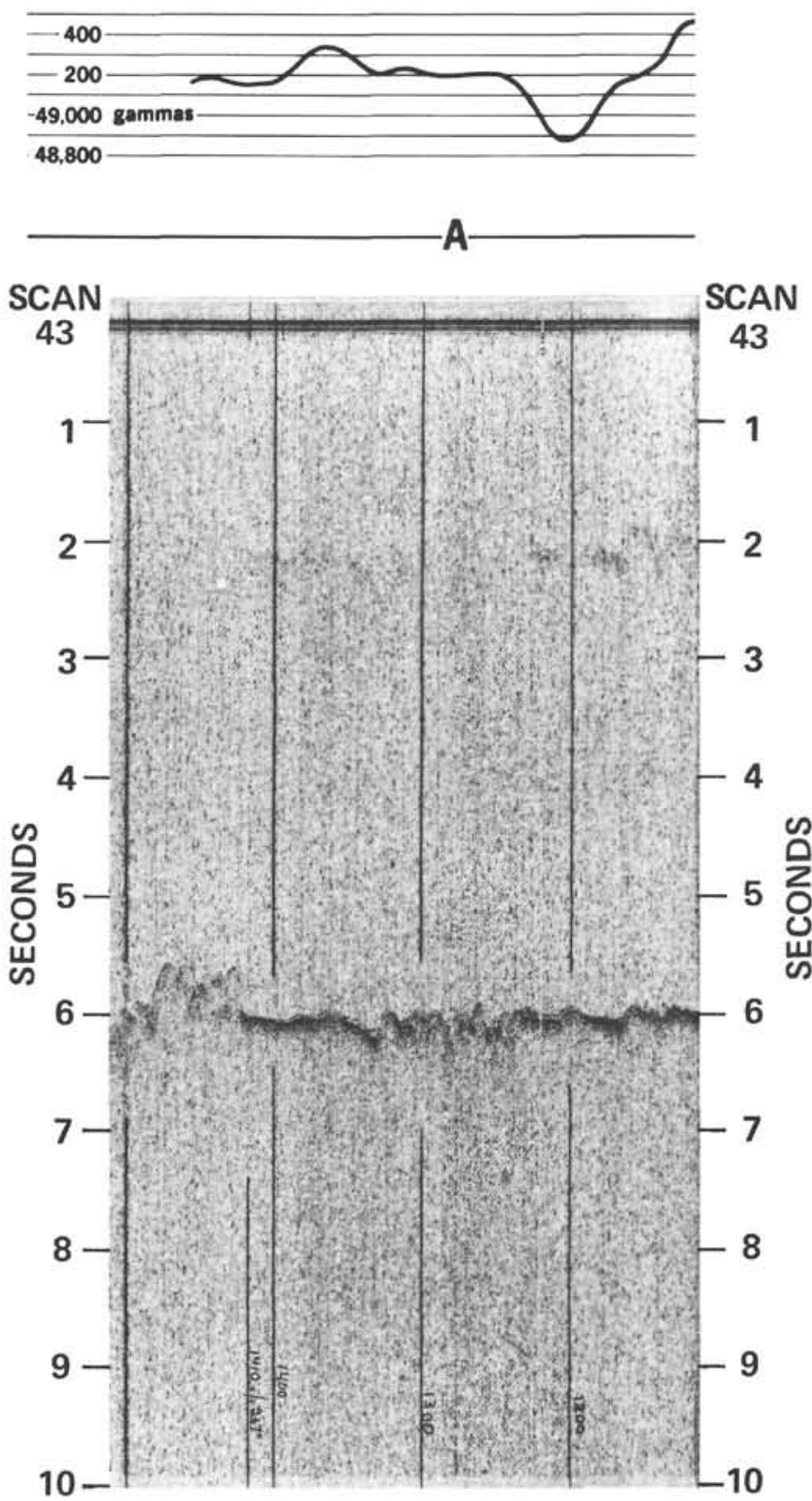

SCAN Survey, Site 6, Track A. 

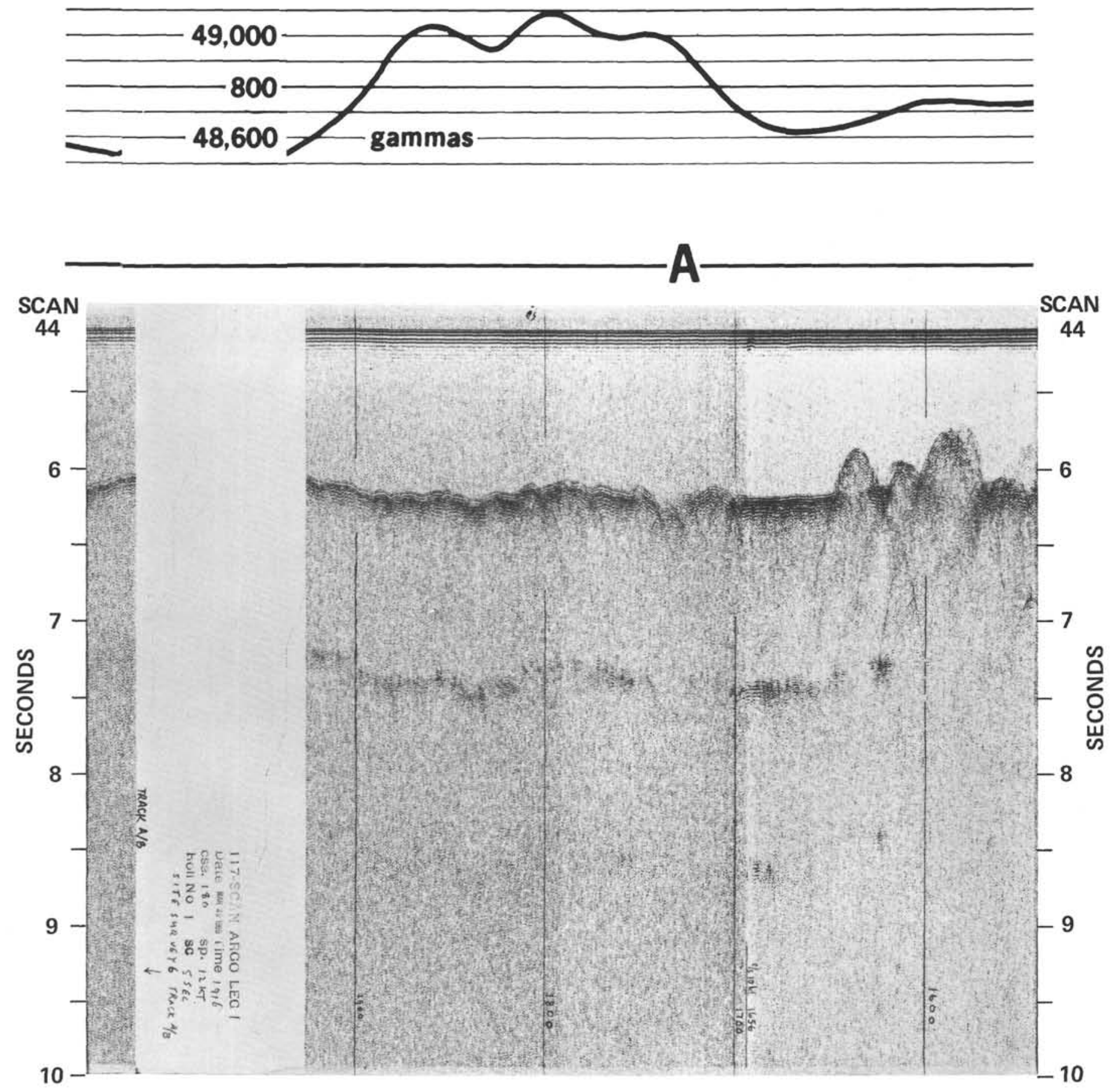

SCAN Survey, Site 6, Track A. 

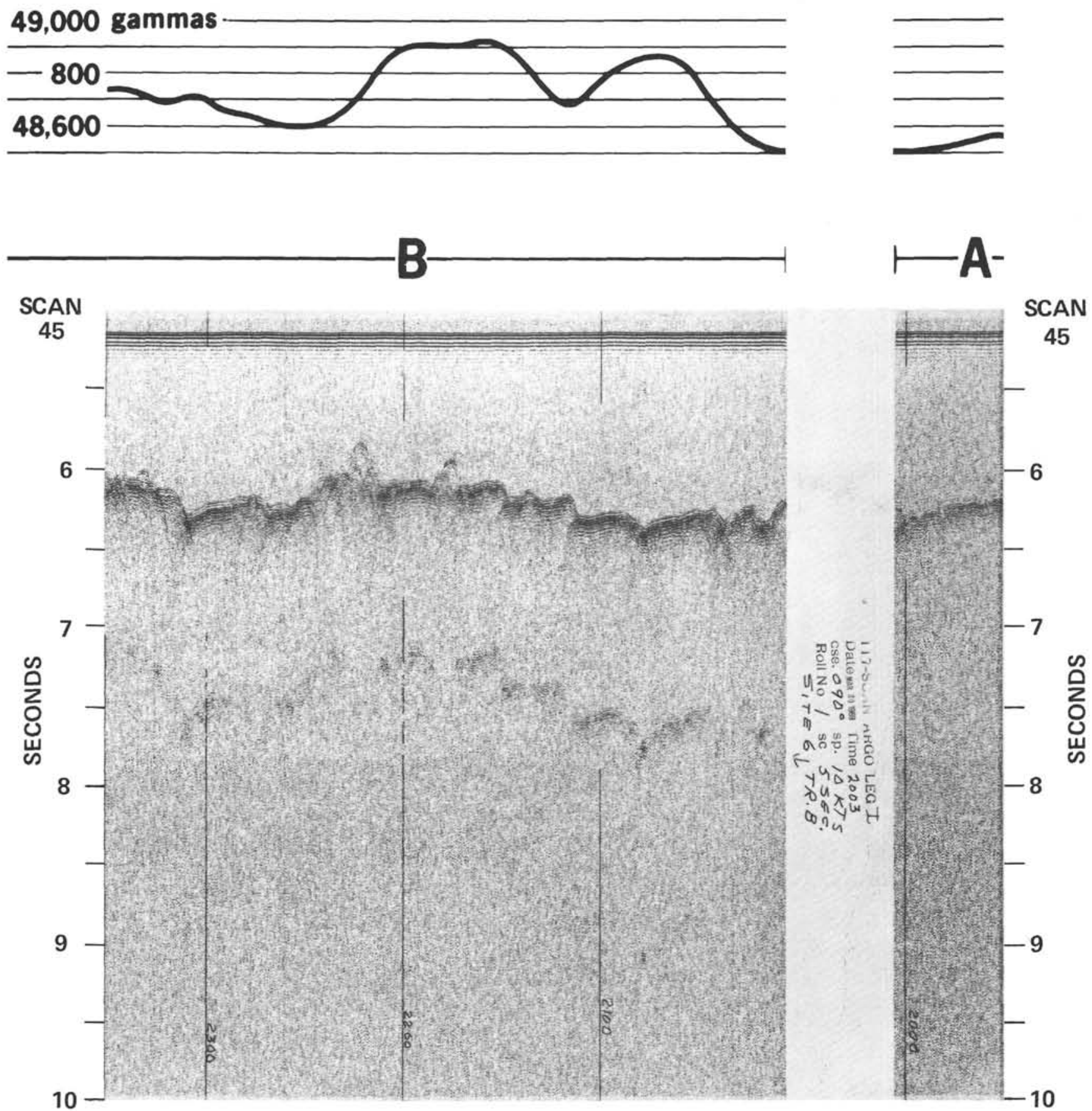

SCAN Survey, Site 6, Tracks $A$ and $B$. 

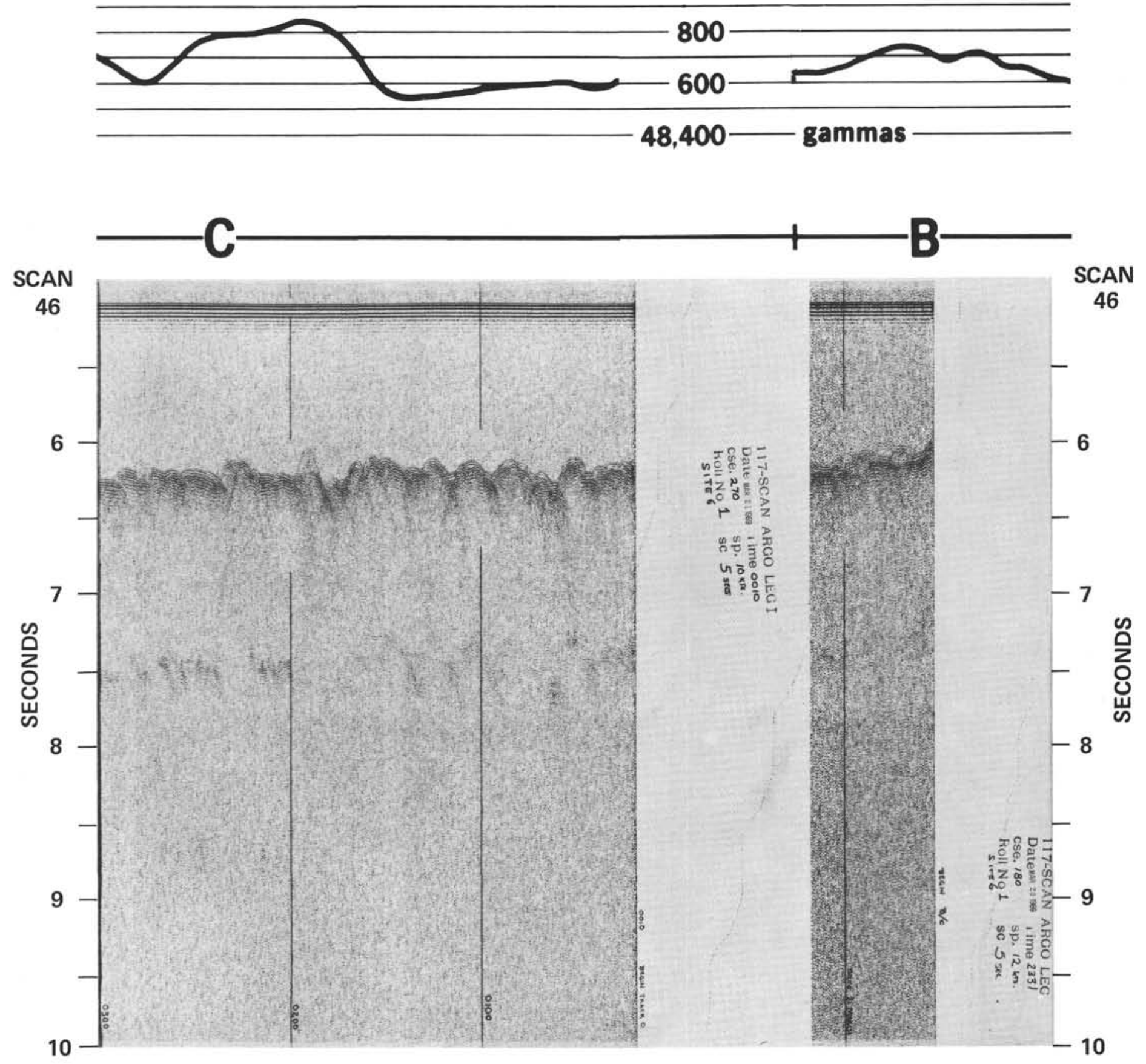

SCAN Survey, Site 6, Tracks B and C. 

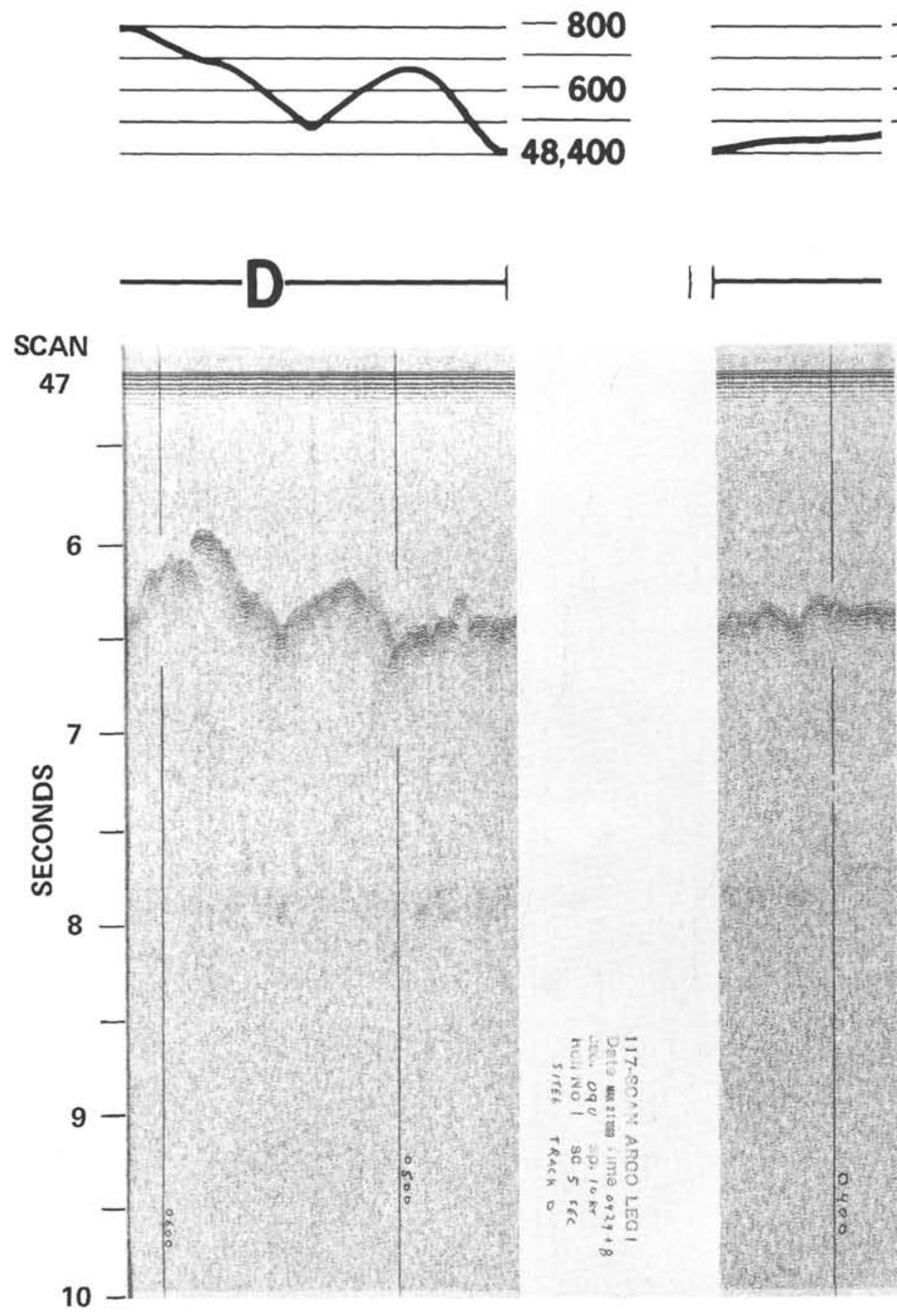

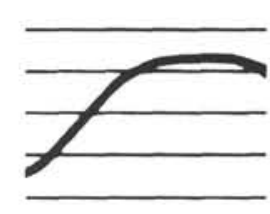

gammas

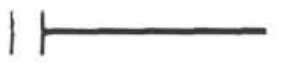

C
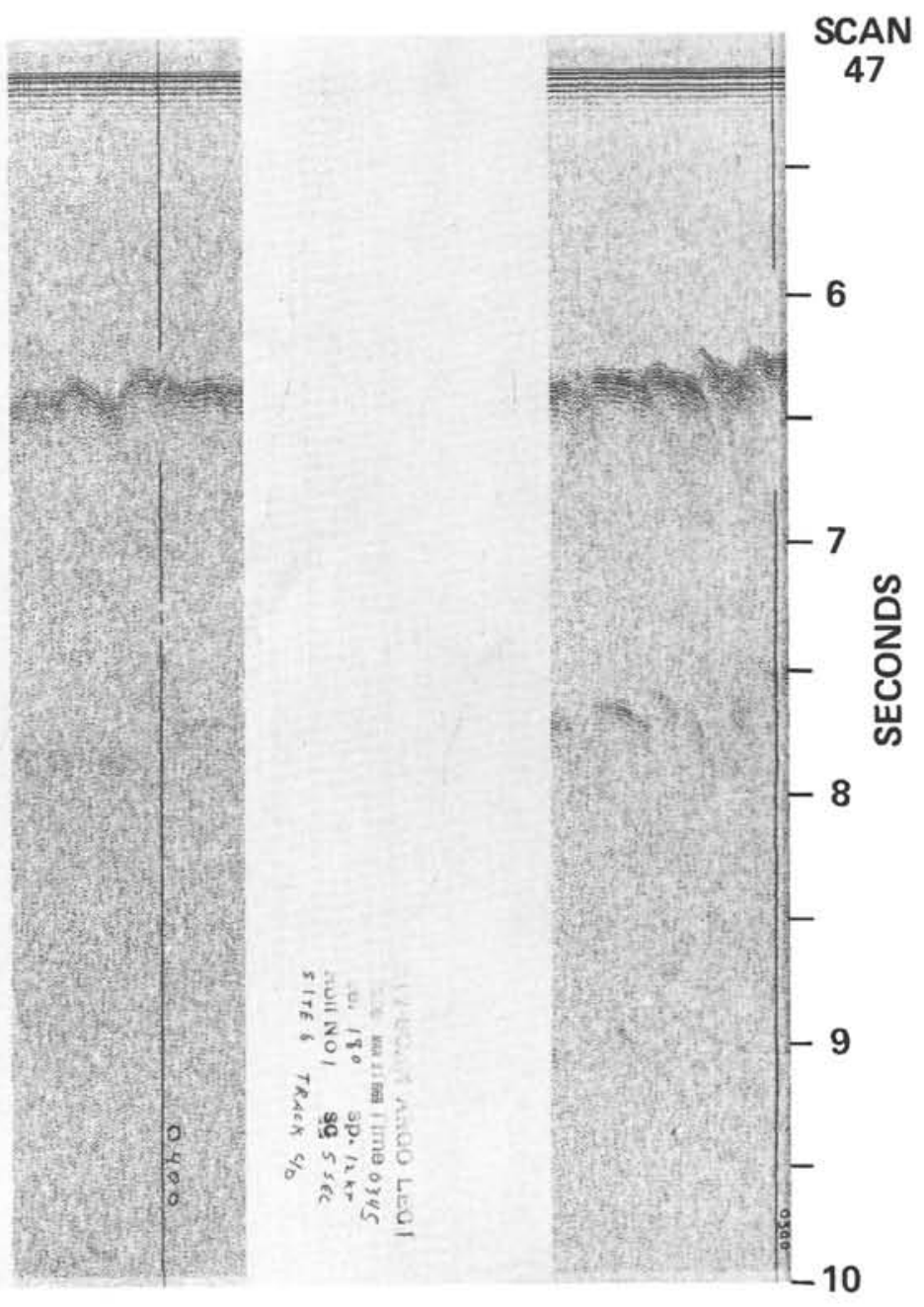

SCAN Survey, Site 6, Tracks $C$ and $D$. 

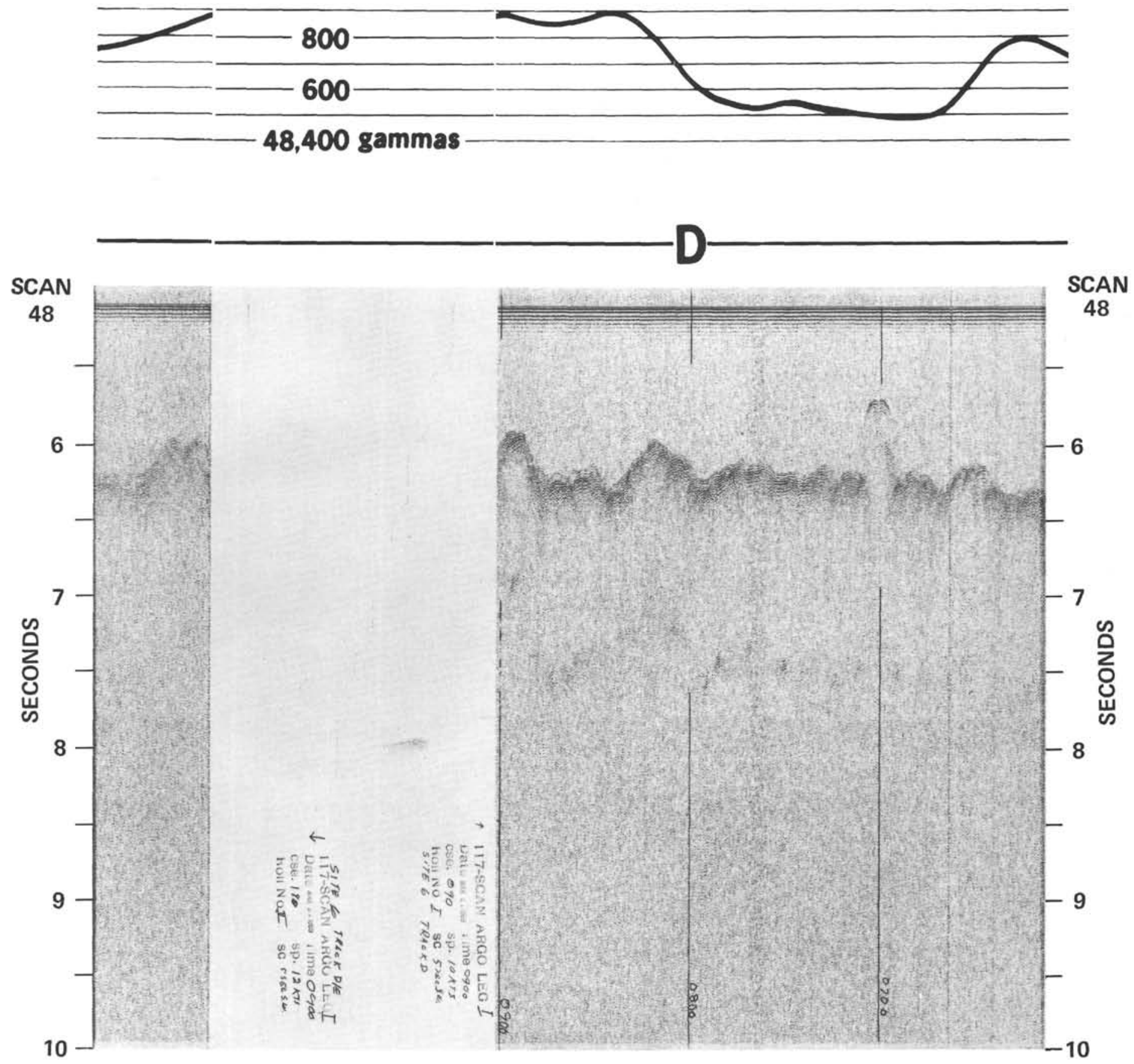

SCAN Survey, Site 6, Track D. 

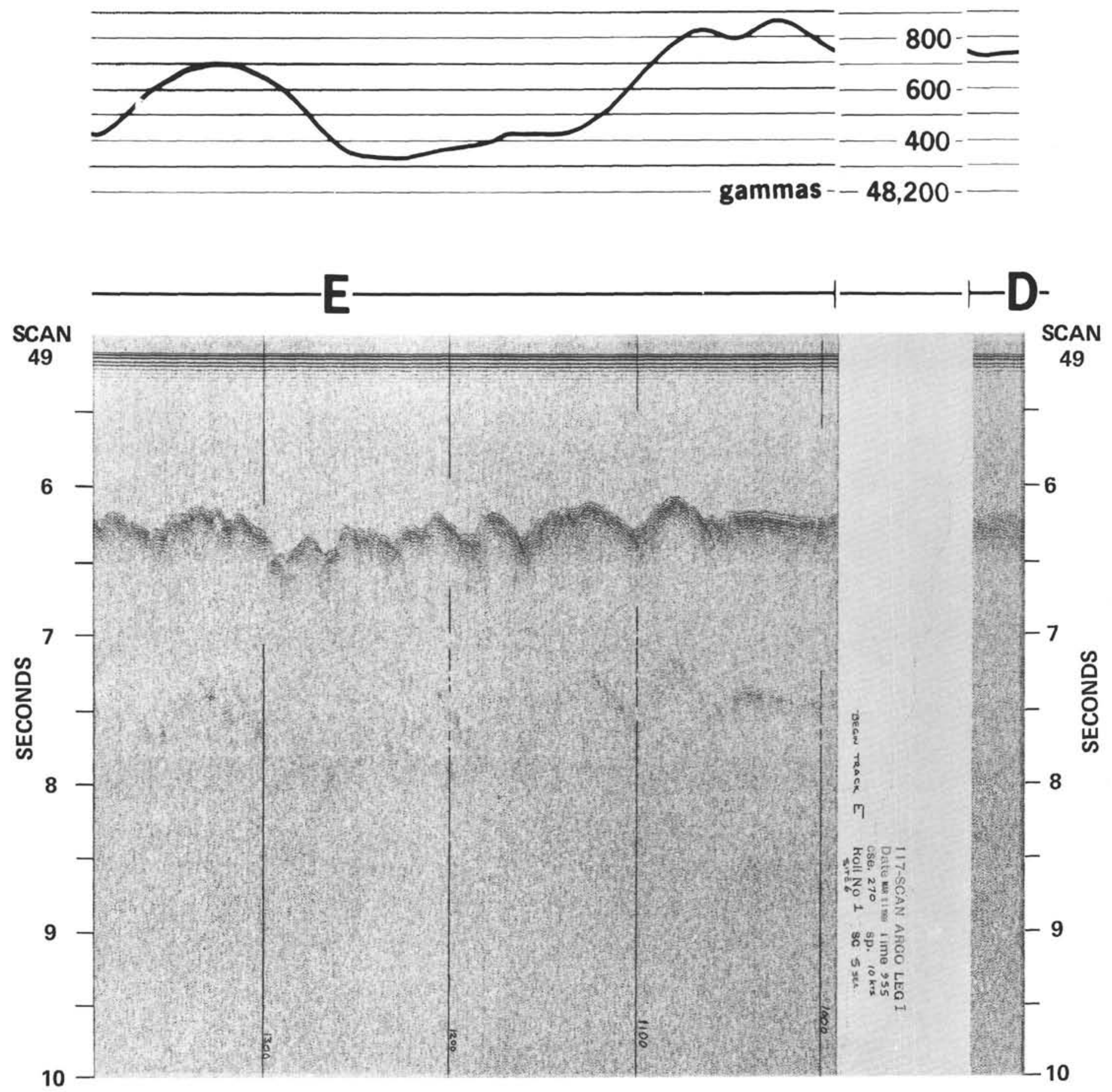

SCAN Survey, Site 6, Tracks D and E. 

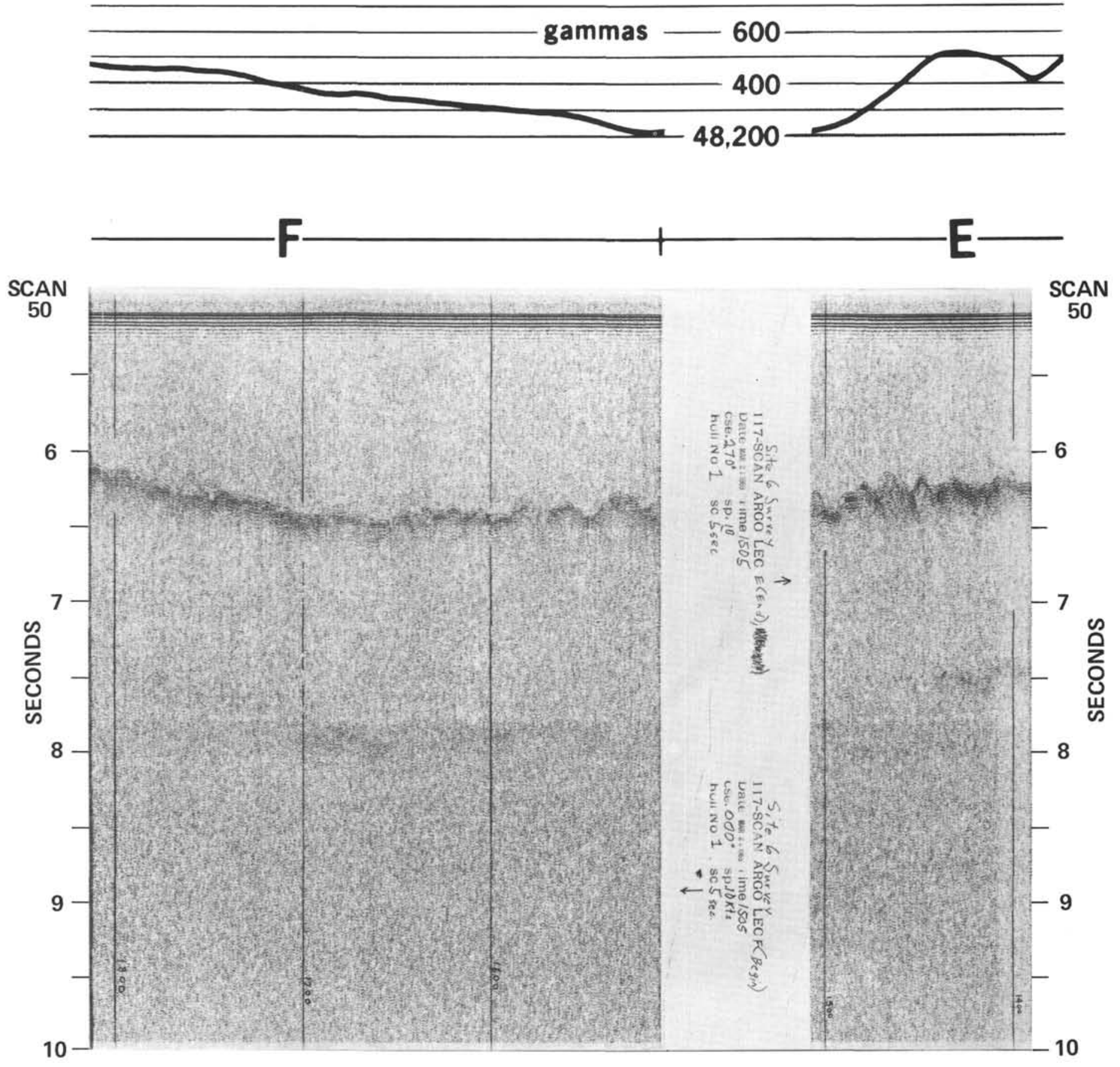

SCAN Survey, Site 6, Tracks $E$ and F. 

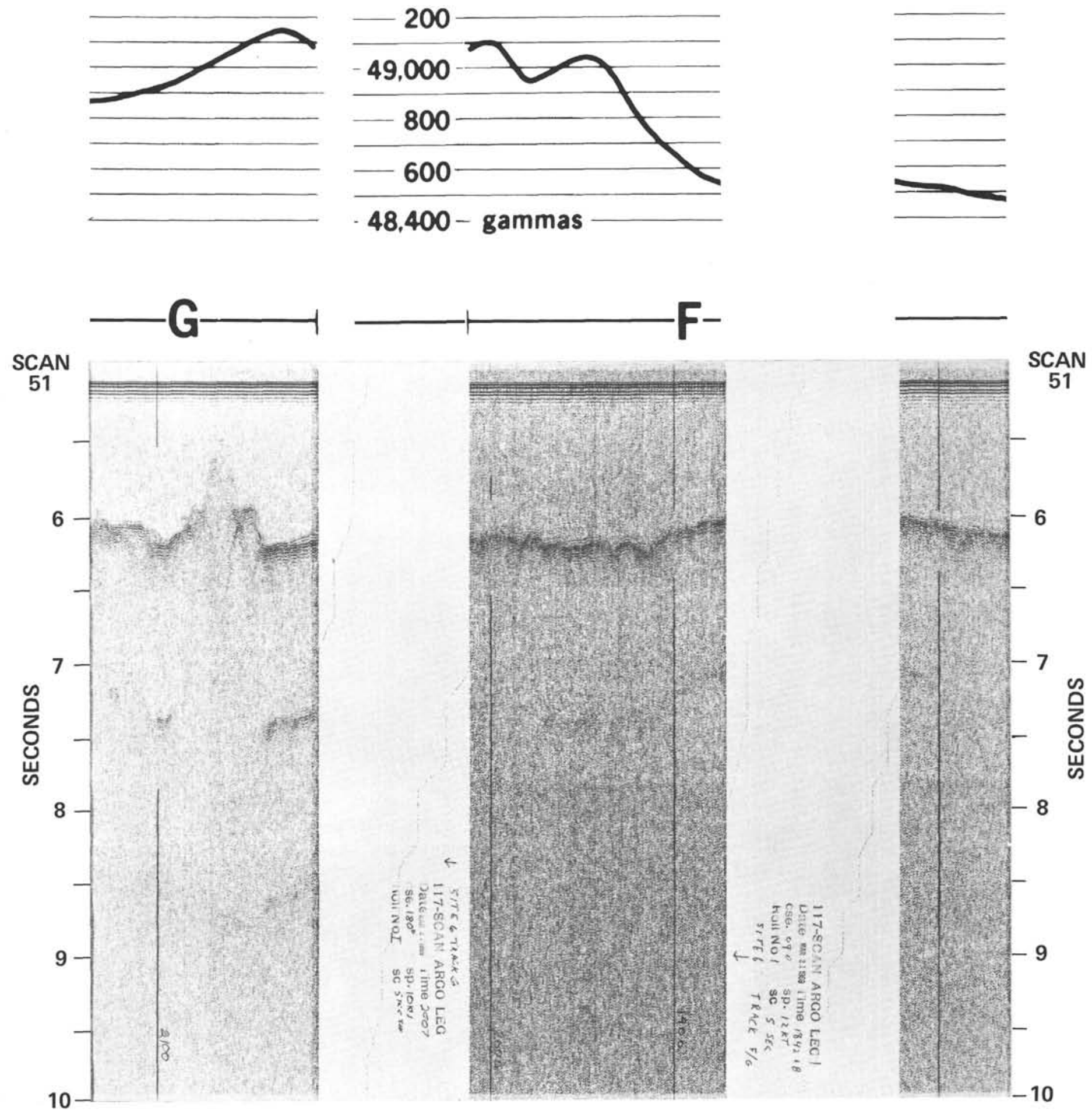

SCAN Survey, Site 6, Tracks $F$ and $G$. 

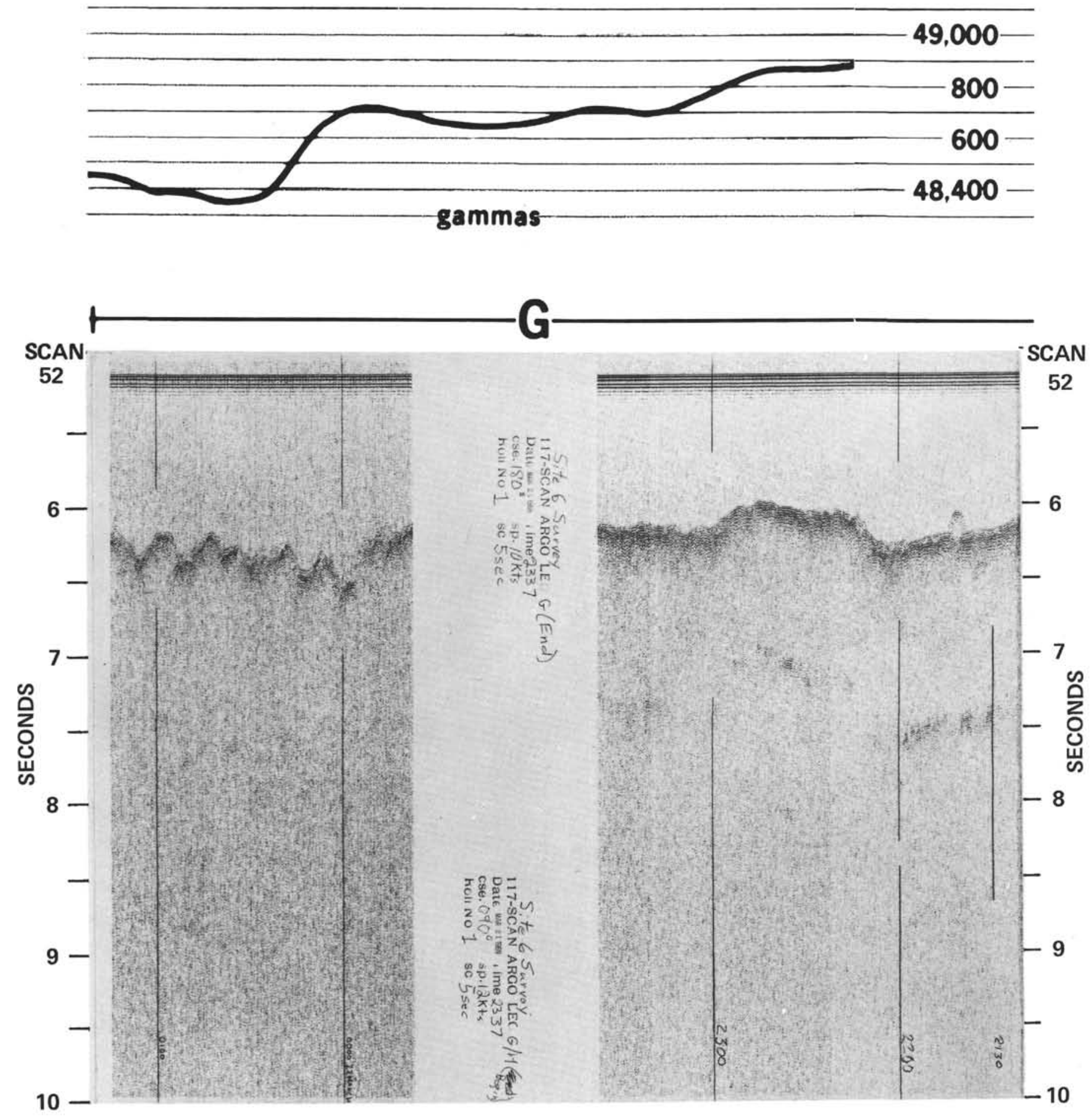

SCAN Survey, Site 6, Track G. 

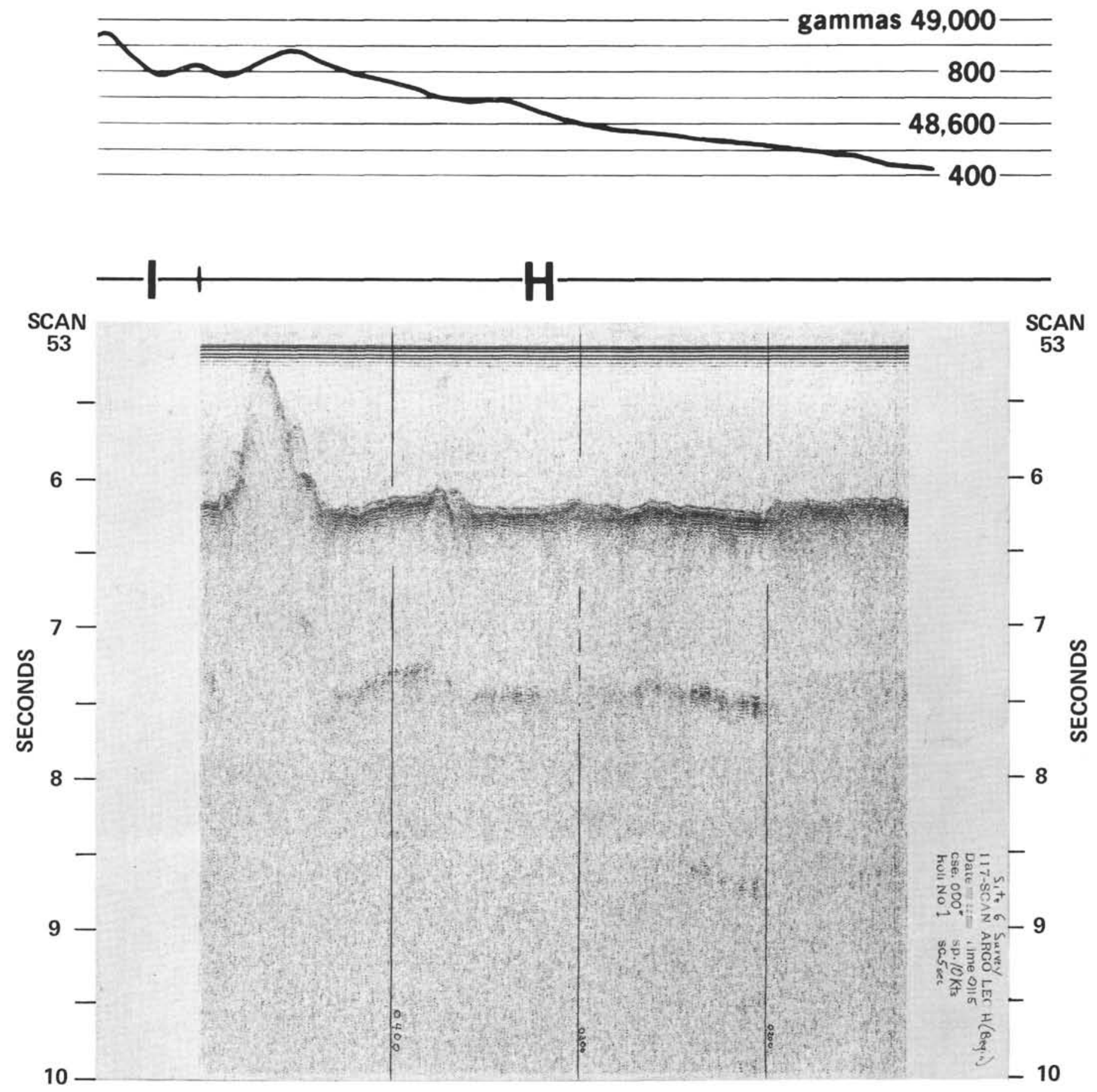

SCAN Survey, Site 6, Tracks $H$ and I. 

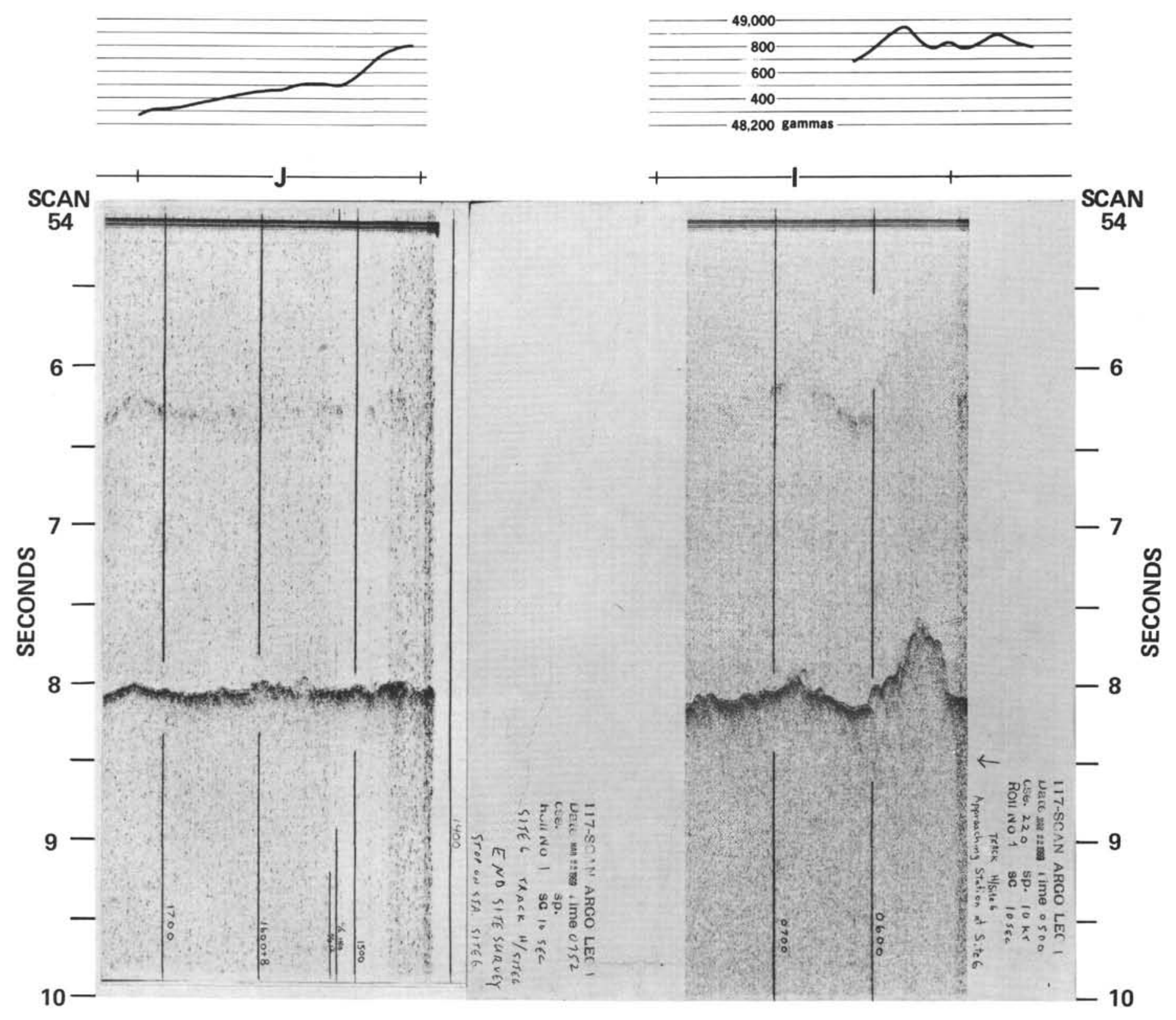

SCAN Survey, Site 6, Tracks I and J. 


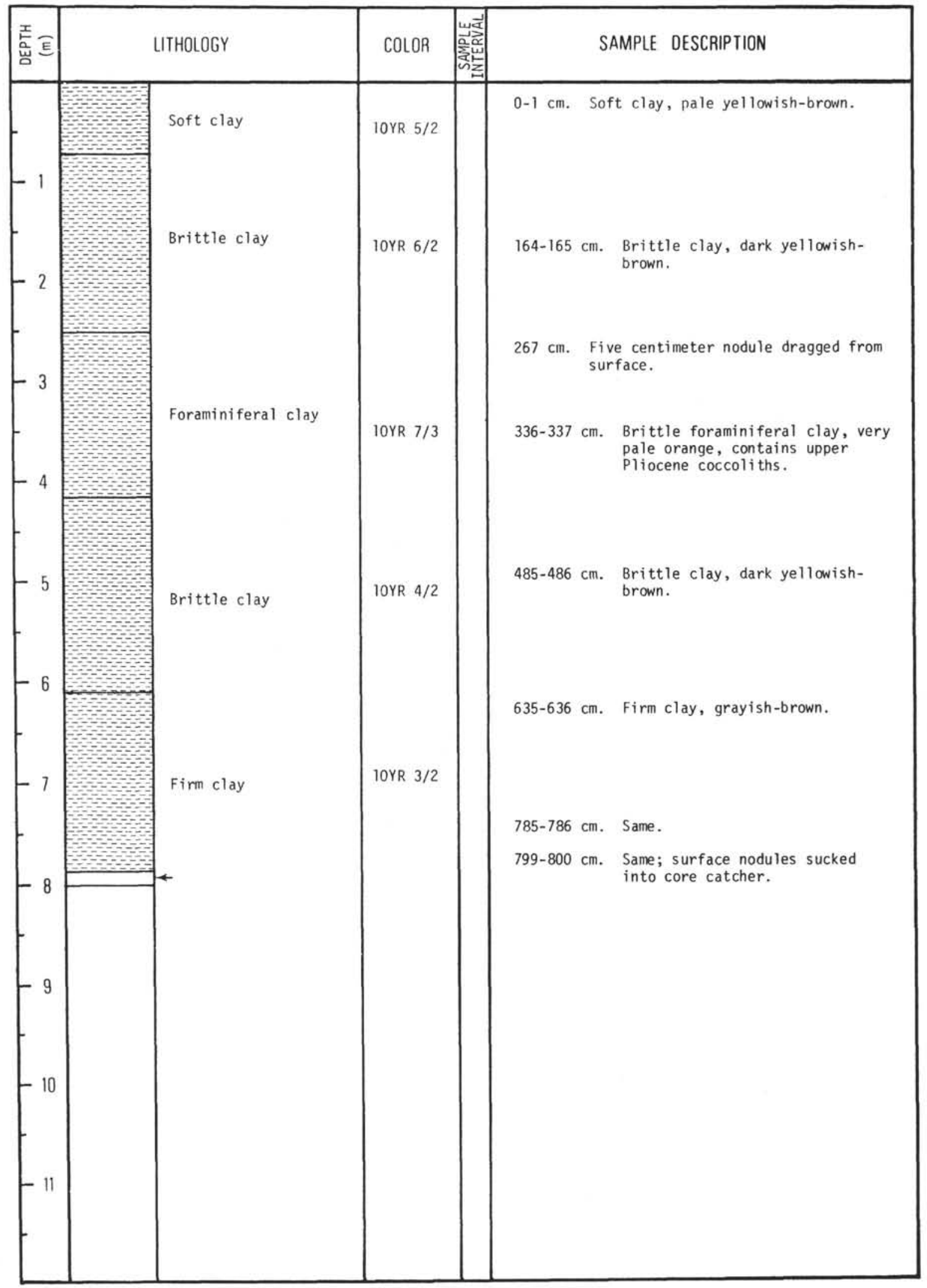

Summary of Piston Core 6. 